\title{
Cross-Cultural Comparisons of Customer Perception at Restaurant Franchises in Beijing, Tokyo, and Seoul
}

\author{
Pilsung Choe ${ }^{* \dagger} \cdot$ Pei-Luen Patrick Rau $\cdot$ Gicheol Jeon \\ Department of Industrial Engineering, Tsinghua University, Beijing, P.R. China

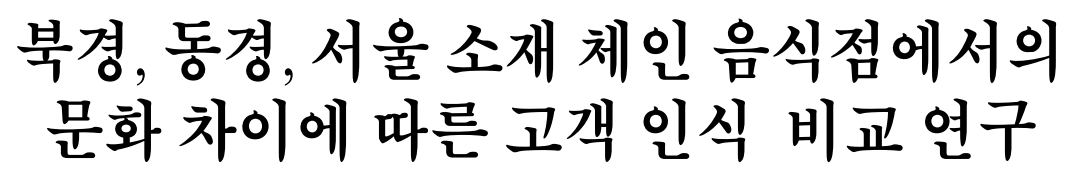 \\ 최필성 · 라우 패트릭 · 전기철 \\ 칭화대 산업공학과
}

\begin{abstract}
Global restaurant franchises are becoming more and more popular in China, Japan, and South Korea. Understanding target customers' needs for restaurant franchises is considered one of the most important factors for their business success. In this study, four domains-food-related domain (FRD), interior-related domain (IRD), staffrelated domain (SRD), and convenience-related domain (CRD)-and 24 elements were classified. A survey with 450 respondents in the three capital cities (Beijing, Tokyo, and Seoul) was then conducted to examine the effect of the factors influencing customer satisfaction. After statistical analysis, thirteen main elements were found as factors influencing customer satisfaction. The analysis result showed that the food-related domain (FRD) was the most important in Beijing. The interior-related domain (IRD) and the convenience-related domain (CRD) were considered the most important in Tokyo and Seoul. Some cultural differences in customer satisfaction were also found. The results provide a guideline for better customer experience management of a restaurant franchise in the three cities.
\end{abstract}

Keywords: Service Quality, Customer Experience, Restaurant Franchise, Cross-Cultural Differences

\section{Introduction}

As a business globalizes, managing the experience of local customers is very important. Customer experience is what customers sense, feel, and think and how they act in relation to a company and its brands (LaSalle and Britton, 2003; Schmitt, 1999; Shaw and Ivens, 2005). Customer experience is often explained at different customer levels, such as nationality, emotion, sense, spirit, and so on because these qualities are subjective perceptions (LaSalle and Britton, 2003; Meyer, 2007; Schmitt, 1999). In this regard, understanding local customers' requirements is very important for a business success.

As a typical globalized business, restaurant franchises are becoming more and more popular. A franchise agreement is a contract between the franchiser and the franchisee. The franchiser is a parent company that has developed some products or services for sale, and the franchisee buys the right to sell them (Chin, 2008; Rubin, 1978).

Recently, restaurant franchises such as McDonald's, KFC, and SUBWAY have become very common in China, Japan, and South Korea, along with their increased influence on the world economy. According to International Monetary Fund

\footnotetext{
This study was supported by a 2009 young researcher grant from Asia Research Center in Tsinghua University.

† Corresponding author : Pilsung Choe, Associate Professor, Department of Industrial Engineering, Tsinghua University, Beijing, China, Tel : +86-10-62796593, Fax :+86-10-62794399, E-mail : pchoe@tsinghua.edu.cn, pschoe@gmail.com

Received November 27, 2012; Revision Received February 6, 2013; Accepted April 9, 2013.
} 
(IMF; http://www.imf.org), the gross domestic products (GDPs) for the year 2012 of China, Japan, and South Korea are the second, third, and fifteenth largest, respectively, among all countries, and their GDP figures have been increasing rapidly. Along with the rapid economic growth of these countries, industrial cooperation or cultural exchange among these three countries is also increasing rapidly. This tendency is more distinct in their capital cities of Beijing, Tokyo, and Seoul. These three cities are seemingly similar because of their geographical proximity, shared history, and close economic relationships. Customer experience, customer behavior, and service quality in these three countries, on the other hand, are considered quite different. Understanding the differences and providing quality services accordingly could make franchise businesses more successful and competitive.

The present study aims to investigate the important factors influencing customer satisfaction at restaurant franchisers and to examine how much different they are among three cities of Beijing, Tokyo, and Seoul. This study then proposes guidelines for designing a restaurant franchise based on quantitative analyses using data obtained from a survey. The analyses will help restaurant franchisers or decision makers efficiently design a restaurant franchise or implement marketing strategies for quality service. This study is expected to ultimately enhance service quality and increase customer satisfaction at restaurant franchises in the three cities under investigation.

\section{Literature Review}

Measuring consumer perceptions related to a service is very useful when analyzing service quality. For example, SERVQUAL (Parasuraman et al., 1988) has been used widely to analyze the quality of some types of services (Devaraj et al., 2002; Gounaris and Dimitriadis, 2003; Jiang et al., 2002,

Table 1. Four domains and 24 elements

\begin{tabular}{c|l}
\hline Domain & \multicolumn{1}{|c}{ Elements } \\
\hline FRD & $\begin{array}{l}\text { (1) Diversity of the menu (2) Service quality of } \\
\text { side dishes (3) Food taste (4) Food decoration } \\
\text { (5) Freshness of food (6) Dish design (7) } \\
\text { Legibility of menus }\end{array}$ \\
\hline IRD & $\begin{array}{l}\text { (8) Seat layout (9) Lighting (10) Wall pictures } \\
\text { (11) Interior smell (12) Interior temperature } \\
\text { (13) Interior colors (14) Background music }\end{array}$ \\
\hline SRD & $\begin{array}{l}\text { (15) Attitude of service, (16) Way of speaking } \\
\text { (17) Promptness of staff, (18) Number of } \\
\text { employees, (19) Cleanliness of employees }\end{array}$ \\
\hline CRD & $\begin{array}{l}\text { (20) Accessibility (21) Waiting time for seating } \\
\text { (22) Waiting area (23) Waiting time for food } \\
\text { (24) Meal fee }\end{array}$ \\
\hline
\end{tabular}

Kang and Bradley, 2002). But, its applicability to a specific service environment has been controversial. So, we developed a conceptual model of customer experiences at restaurant franchises based on a literature review and brainstorming to ensure our study design was suitable to examine restaurant franchising. After reviewing other studies related to customer experience at restaurant franchises, four domains and 24 elements influencing customer satisfaction at restaurants were initially identified as shown in $\langle$ Table 1$\rangle$. The four domains include the food-related domain (FRD), interior design-related domain (IRD), staff-related domain (SRD), and convenience-related domain (CRD).

\subsection{Food-Related Domain}

The food-related domain (FRD) included food and menurelated factors. Food is the main service at restaurants. A menu is the list of dishes that customers can order. Menu was included in the FRD in that diverse dishes in the menu can increase the possibility of ordering the food that a customer wants to eat. Many researchers have mentioned that food is the most important attribute that increases customer loyalty to a restaurant (Clark and Wood, 1998; Davis and Vollmann, 1990; Kivela et al., 2000; Susskind and Chan, 2000; Sulek and Hensley, 2004). Kivela et al. (2000) found that the first and the last impressions have the greatest impact on repeat-purchase intentions, followed by excellence in service and food quality. Sulek and Hensley (2004) investigated the relative importance of food quality, physical settings, and service in a full-service restaurant and reported that food quality is the most significant predictor of customer satisfaction. Food quality involves taste, presentation, textures, colors, temperature, variety, healthy options, freshness, size of the portions, and entrée complexity (Sulek and Hensley, 2004). Related to menus, a well organized menu has been known to help customers easily interpret the food and expected food quality (Parsa and Kahn, 1991, 1989). Service quality of side dishes (Han, 2009) and dish design (Parsa and Kahn, 1989) have been classified as factors influencing customer satisfaction in other research.

\subsection{Interior Design-Related Domain}

Interior design has been considered another important factor for quality service at restaurants. In the present study's context, the interior design-related domain (IRD) included factors related to interior setting (Susskind and Chan, 2000), the physical environment (Lambert and Watson 1984, Wakefield and Blodgett, 1999), atmosphere or background music (Milliman, 1986; Smith and Curnow, 1966), and seat layouts or seating comfort (Sulek and Hensley, 2004; Wakefield and Blodgett, 1996) all of which influenced customers' cognitions, emotions, feelings, or behaviors. In addition to these elements, interior smells were considered a factor that influenced customer satisfaction (Han, 2009). 


\subsection{Staff-Related Domain}

In addition to the food and design aspects of a restaurant, staffing has been considered an important factor affecting customer satisfaction. The staff-related domain (SRD) included elements that influence interactions with customers. The first mission of working staff at restaurants is to make customers comfortable (Erickson, 2004). They have to properly speak, move, and serve (Testa and Sipe, 2006; Whyte, 1964) the restaurant's customers. Customers' perceptions regarding how they are treated by working staff affects customer satisfaction (Fitzsimmons and Maurer, 1991; Smith et al., 1999; Sparrow et al., 1992). Staff skills should include sensitivity, presence, helpfulness, friendliness, cleanliness, and politeness (Mittal and Lassar, 1996, Bitner, 1990; Knutson, 2000).

\subsection{Convenience-Related Domain}

Convenience can be considered as a significant advantage of restaurant franchises, because they are seen everywhere and the menu and taste have been standardized and verified. The convenience-related domain (CRD) includes elements related to ease-of-use in terms of time, place, and cost. Location is an important factor to customer satisfaction of a restaurant (Namkung and Jang, 2007) and convenience and accessibility can be considered an important strength of restaurant franchisees. Waiting time (Sulek and Hensley, 2004; Clark and Wood, 1998) or the conditions in the waiting area (Baker and Cameron, 1996) have also been mentioned as important factors in customer experience at restaurants. Perceived waiting time, for example, can be changed based on the condition of the waiting area (Baker and Cameron, 1996). A roomy waiting area tends to increase a customer's willingness to wait for seating even if the restaurant is busy (Davis and Vollmann, 1990). In addition, perceived service quality has been researched as a function of the service price (Dube et al., 1999; Ryu and Jang, 2007; Varki and Colgate, 2001; Zeithaml, 1988).

\subsection{Research Framework}

Customer experience at restaurant franchises in different countries can be very different, because cultures influencing customer experience differ among countries. Cross-cultural differences can be explained with many factors such as the economy, history, politics, education, beliefs, art, morals, customs, laws, and so on (Pheng and Yuquan, 2002). China, Japan, and South Korea are considered to have different cultures in that they differ in the factors noted above. The capital cities of these three countries-Beijing, Tokyo, and Seoulwere chosen for the present research comparing cross-cultural differences because those capital cities are very influential in their respective national economies.
$<$ Figure 1 $>$ illustrates a framework of the present study describing customer experiences at restaurant franchises.

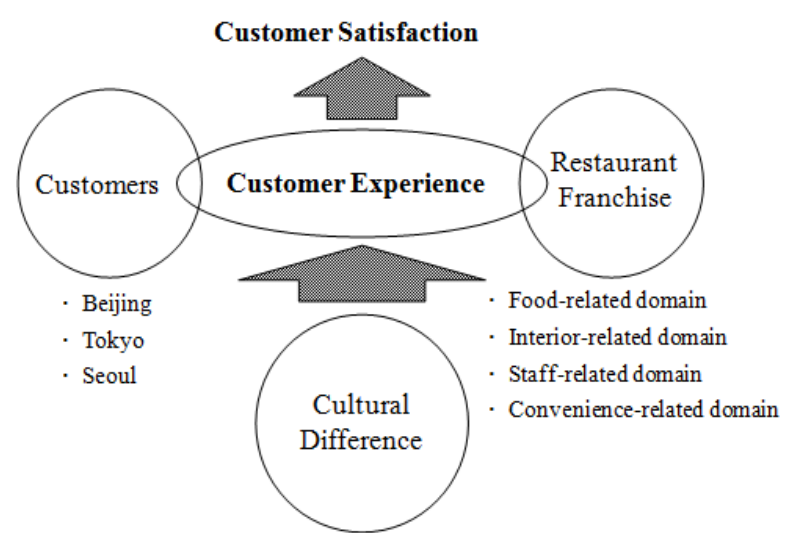

Figure 1. Research framework of customer experience at restaurant franchises

As shown in the figure, this study hypothesized that customer experience at restaurant franchises is influenced mainly by four domains (FRD, IRD, SRD, CRD) with a collective total of 24 elements. The exhibit also shows that the degree of the impact by factors-domains and elements-differ among the three cities.

This study hypothesized that customer experience at restaurant franchises is influenced mainly by four domains (FRD, IRD, SRD, CRD) with a total of 24 elements.

\section{Method}

To examine the present study's research questions, a survey was conducted in the three capital cities, Beijing, Tokyo, and Seoul, between March and September 2010. A questionnaire asking about the respondents' experiences at the restaurant franchise was used for the survey.

\subsection{Questionnaire}

A questionnaire was developed to measure customers' perceptions of the four domains and 24 elements affecting their experiences at restaurant franchises $<$ Appendix $A>$. The questionnaire was first developed in English and then translated into Chinese, Japanese, and Korean for the respondents within each city. To secure translation validity, the translation-retranslation approach was used. In addition, to improve the questionnaire, a pilot survey was conducted with 30 students representing the three nationalities (China, Japan, and South Korea) at Tsinghua University in China. The questionnaire was composed of four parts including a prologue, demographic information, the main questions, and an epilogue (Lehto and Buck, 2008). The demographic information included the frequency of using restaurant franchises in the 
past in addition to asking respondents for their basic information such as age, gender, and income. In this demographic information part, respondents were asked to choose one restaurant franchise they visited most often and to answer the main questions based on their experiences at that restaurant's franchises. The questionnaire included 24 questions intended to measure the customers' perceptions on each of the 24 elements $\langle$ Table $1>$. One additional question about general customer satisfaction at the restaurant franchise was included as a dependent variable. A 7-point Likert scale was used to capture respondents' answers.

\subsection{Respondents}

A total of 450 effective questionnaires (150 questionnaires per city) were collected after excluding 56 incomplete questionnaires. The survey respondents were chosen mainly near universities (Tsinghua University in Beijing, Waseda University in Tokyo, and Hanyang University in Seoul) because restaurant franchises are very popular within college communities in these cities. As such, the majority of the respondents were college students (59\% in Beijing, $77 \%$ in Tokyo, and $62 \%$ in Seoul). The number of males and females were fairly balanced in Beijing and Tokyo. In Seoul, however, females $(69 \%)$ were the majority. The restaurant franchises they most preferred were somewhat different among three cities. In each case, the number in parentheses indicates the frequency of answers. Respondents in Beijing preferred McDonald's (27), KFC (26), Ma La You Huo (13), Xia Bu Xia $\mathrm{Bu}$ (11), and Yong He Da Wang (9). In Tokyo they favored Saizeriya (46), McDonald's (22), Gusto (20), and Coco ichibanya (20). In Seoul the top franchises were Outback Steak House (28), McDonald's (18), Kim Bap Chun Guk (11), and Ashley (11).

\section{Analyses and Results}

Cronbach's alpha (Cronbach, 1951) was conducted initially for all of the data from the three cities to check the internal consistency. The Cronbach's alpha coefficients in each domain were 0.7 or higher $(0.70,0.79,0.84$, and 0.70 for FRD, IRD, SRD, and CRD, respectively), which indicates that the questionnaire could be considered internally consistent. Factor analysis was then conducted to confirm the four domains as factors. A stepwise multiple linear regression analysis was then performed to determine the relationship between the four domains and customer satisfaction.

\subsection{Factor Analysis}

An initial confirmatory factor analysis was conducted to find main elements for positive customer experiences. After obtaining the rotated component matrix with 24 elements, el- ements whose factor loadings were less than 0.6 were removed for analysis. From the analysis, 13 out of the 24 elements were considered main elements. These included : wall pictures, lighting, interior color, interior smell, attitude of service, way of speaking, promptness of staff, number of employees, food taste, food decoration, waiting time for seating, waiting time for food, and accessibility. The eleven elements that were not in the four factors were regarded as relatively unimportant to increase customer satisfaction at restaurant franchises, and the 13 elements were then considered for further analysis.

Factor analysis with the elements was conducted. As shown in $\langle$ Table 2>, the upper four components explained about $68 \%$ of the total variance. Each initial eigenvalues for the four components were greater than 1 .

Table 2. Variance ratios for top four components

\begin{tabular}{c|c|c|c|c}
\hline Item & Comp. & Total & $\begin{array}{c}\% \text { of } \\
\text { Variance }\end{array}$ & $\begin{array}{c}\text { Cumulative } \\
\%\end{array}$ \\
\hline & 1 & 4.986 & 38.352 & 38.352 \\
Initial & 2 & 1.531 & 11.779 & 50.132 \\
Eigenvalues & 3 & 1.322 & 10.166 & 60.298 \\
& 4 & 1.028 & 7.911 & 68.209 \\
\hline Extraction & 1 & 4.986 & 38.352 & 38.352 \\
Sums of & 2 & 1.531 & 11.779 & 50.132 \\
Squared & 3 & 1.322 & 10.166 & 60.298 \\
Loadings & 4 & 1.028 & 7.911 & 68.209 \\
\hline Rotation Sums & 1 & 2.735 & 21.041 & 21.041 \\
of Squared & 2 & 2.484 & 19.109 & 40.150 \\
Loadings & 3 & 1.872 & 14.397 & 54.547 \\
& 4 & 1.776 & 13.662 & 68.209 \\
\hline
\end{tabular}

Table 3. Rotated component matrix

\begin{tabular}{l|c|c|c|c}
\hline \multirow{2}{*}{ Elements } & \multicolumn{4}{|c}{ Component } \\
\cline { 2 - 5 } & 1 & 2 & 3 & 4 \\
\hline Way of speaking & .842 & & & \\
Attitude of service & .842 & & & \\
Promptness of staff & .731 & & & \\
Number of employees & .666 & & & \\
\hline Wall pictures & & .816 & & \\
Lighting & & .702 & & \\
Interior smell & & .698 & & \\
Interior color & & .680 & & \\
\hline Waiting time for seating & & & .820 & \\
Waiting time for food & & & .796 & \\
Accessibility & & & .617 & \\
\hline Food taste & & & & .825 \\
Food decoration & & & & .745 \\
\hline
\end{tabular}

The final rotated component matrix was then obtained $<$ Table 3$\rangle$. As shown in $\langle$ Table $3>$, all factor loadings great- 
er than 0.6 after the varimax rotation were included in the matrix. The results revealed that the four factors are well represented with the 13 elements. More specifically, (1) attitude of service, way of speaking, promptness of staff, and number of employees; (2) wall pictures, lighting, interior color, and interior smell; (3) waiting time for seating, waiting time for food, and accessibility; and (4) food taste and food decoration were grouped as factors. The latter results support the fact that the four factors from the factor analysis correspond to four domains of SRD, IRD, CRD, and FRD, which were defined at the beginning of the research.

\subsection{Regression}

A stepwise multiple linear regression analysis was conducted to determine the relationship between the four domains as independent variables and customer satisfaction (at the restaurant franchise) as the dependent variables. As shown in $\langle$ Table 4$\rangle$, all domains turned out to be significant predictors of customer satisfaction $(a=0.05)$.

Table 4. Regression analysis with domains

\begin{tabular}{|c|c|c|c|c|}
\hline City & Ind. var. & Coeff. & p-value & $R^{2}$ \\
\hline Beijing & $\begin{array}{c}\text { (Constant) } \\
\text { FRD } \\
\text { CRD } \\
\text { IRD } \\
\text { SRD }\end{array}$ & $\begin{array}{l}0.223 \\
0.367 \\
0.315 \\
0.258 \\
0.252\end{array}$ & $\begin{array}{l}0.001 \\
0.000 \\
0.000 \\
0.000 \\
0.000\end{array}$ & 0.381 \\
\hline Tokyo & $\begin{array}{c}\text { (Constant) } \\
\text { IRD } \\
\text { SRD } \\
\text { FRD } \\
\text { CRD }\end{array}$ & $\begin{array}{r}-0.068 \\
0.451 \\
0.389 \\
0.295 \\
0.265\end{array}$ & $\begin{array}{l}0.298 \\
0.000 \\
0.000 \\
0.000 \\
0.000\end{array}$ & 0.468 \\
\hline Seoul & $\begin{array}{c}\text { (Constant) } \\
\text { CRD } \\
\text { FRD } \\
\text { SRD } \\
\text { IRD }\end{array}$ & $\begin{array}{r}-0.181 \\
0.342 \\
0.329 \\
0.273 \\
0.178 \\
\end{array}$ & $\begin{array}{l}0.010 \\
0.000 \\
0.000 \\
0.000 \\
0.005\end{array}$ & 0.310 \\
\hline Overall & $\begin{array}{c}\text { (Constant) } \\
\text { FRD } \\
\text { CRD } \\
\text { IRD } \\
\text { SRD }\end{array}$ & $\begin{array}{l}1.270 \\
0.315 \\
0.231 \\
0.150 \\
0.106\end{array}$ & $\begin{array}{l}0.000 \\
0.000 \\
0.000 \\
0.000 \\
0.000\end{array}$ & 0.435 \\
\hline
\end{tabular}

Overall, the FRD was considered the most important for customer satisfaction with the regression coefficient, 0.315 . But, the importance of the FRD varied by city (first in Beijing, third in Tokyo, and second in Seoul). The FRD was the most important domain in Beijing. For the Japanese (respondents in Tokyo), the most important domain was IRD, whereas it was the least important in Beijing and Seoul. In Tokyo, the SRD was considered more to be important than the FRD and the CRD, which were the first two important factors in Tokyo and Seoul. The CRD for Koreans was the most important, whereas it was considered the least in Tokyo.

Another stepwise multiple linear regression analysis was conducted $(a=0.05)$ with the $13<$ Table $5>$. Interestingly, accessibility was overall the most important element influencing customer satisfaction with the regression coefficient of 0.220 . This results demonstrate the importance of restaurant franchise be accessible, which is related to the number of franchises, transportation, and location. Food taste (0.207), food decoration (0.152), way of speaking (0.139), waiting time for food (0.125), and lighting (0.122) were also significantly important for customer satisfaction. Other elements, including attitude of service, promptness of staff, number of employees, interior color, interior smell, waiting time for seating, and food decoration were eliminated in the stepwise procedure of the analysis.

Food taste was important in all three cities. Beijing and Seoul showed the same tendencies as the overall result. Lighting, however, was the most important for Japanese respondents. Even accessibility and way of speaking were considered more important than food taste in Tokyo. In fact, only in Tokyo were lighting and way of speaking found to be important elements to customer satisfaction. In addition to food taste, waiting time for food was the next important element in Seoul, which showed Koreans are impatient when being served in franchise restaurants.

Table 5. Regression analysis with elements

\begin{tabular}{l|c|r|c|c}
\hline City & Ind. var. & Coeff. & $p$-value & $R^{2}$ \\
\hline \multirow{5}{*}{ Beijing } & (Constant) & -2.920 & 0.000 & \\
& Food taste & 0.357 & 0.000 & 0.415 \\
& Wall pictures & 0.164 & 0.001 & 0.415 \\
& Accessibility & 0.127 & 0.017 & \\
\hline \multirow{5}{*}{ Tokyo } & (Constant) & -4.139 & 0.000 & \\
& Lighting & 0.244 & 0.000 & \\
& Accessibility & 0.231 & 0.000 & 0.536 \\
& Way of speaking & 0.222 & 0.000 & \\
& Food taste & 0.150 & 0.001 & \\
\hline \multirow{5}{*}{ Seoul } & (Constant) & -3.407 & 0.000 & \\
& Food taste & 0.290 & 0.000 & 0.344 \\
& Waiting time for food & 0.250 & 0.000 & \\
& Wall pictures & 0.140 & 0.002 & \\
\hline \multirow{5}{*}{ Overall } & (Constant) & -3.576 & 0.000 & \\
& Accessibility & 0.220 & 0.000 & \\
& Food taste & 0.207 & 0.000 & \multirow{1}{*}{ Food decoration } \\
& Way of speaking & 0.152 & 0.001 & 0.407 \\
& Waiting time for food & 0.125 & 0.001 & \\
& Lighting & 0.122 & 0.002 & \\
\hline
\end{tabular}

\subsection{Duncan's Multiple Range Test}

To check for any specific differences among the cities, Duncan's multiple range test was conducted $(a=0.05)$ after confirming a significant difference using ANOVA $(a=0.05)$ 
on a domain or an element. In terms of domains, the FRD was the only domain showing significance, with the other domains remaining insignificant. As shown in $\langle$ Table $6>$, all of the three cities showed significant difference on the FRD ( $a$ $=0.05$ ). Respondents in Beijing (Chinese) were influenced by the FRD with 19.94; Koreans and Japanese followed with 18.47 and 17.51 , respectively.

Table 6. Duncan's multiple range test with the FRD

\begin{tabular}{c|c|c|c}
\hline City & Subset1 & Subset2 & Subset3 \\
\hline Tokyo & 17.51 & & \\
\hline Seoul & & 18.47 & \\
\hline Beijing & & & 19.94 \\
\hline
\end{tabular}

Among the 13 elements, food taste, food decoration, interior smell, interior color, waiting time for seating, and accessibility, showed significant differences $(a=0.05)$ among the three counties $\langle$ Table 7$\rangle$. We found no significant difference with the elements in the SRD.

Table 7. Duncan's multiple range test with elements

(a) Food taste

(b) Food decoration

\begin{tabular}{|c|c|c|c|c|c|c|}
\hline City & Subset1 & Subset 2 & City & Subset1 & Subset2 & Subset3 \\
\hline Tokyo & 4.85 & & Tokyo & 3.96 & & \\
\hline Seoul & 5.05 & 5.05 & Seoul & & 4.51 & \\
\hline Beijing & & 5.17 & Beijing & & & 5.01 \\
\hline
\end{tabular}

(c) Interior smell

\begin{tabular}{|c|c|c|c|c|c|}
\hline City & Subset1 & Subset2 & City & Subset1 & Subset2 \\
\hline Seoul & 4.02 & & Tokyo & 4.49 & \\
\hline Beijing & & 4.54 & Beijing & 4.74 & 4.74 \\
\hline Tokyo & & 4.65 & Seoul & & 4.92 \\
\hline
\end{tabular}

(e) Waiting time for seating

\begin{tabular}{|c|c|c|c|c|c|}
\hline City & Subset1 & Subset2 & City & Subset1 & Subset2 \\
\hline Beijing & 4.45 & & Seoul & 4.95 & \\
\hline Tokyo & & 4.87 & Beijing & 5.24 & 5.24 \\
\hline Seoul & & 4.94 & Tokyo & & 5.32 \\
\hline
\end{tabular}

Food taste showed a significant difference between Japanese (4.85) and Chinese (5.17) respondents. This result revea 1s that Chinese expectations for food at the restaurant franchise are higher than those of the Japanese. But, no significant difference between the Japanese and Koreans or the Koreans and the Chinese was found on food taste. Food decoration was more important to Chinese (5.01) than to Koreans (4.51) or to Japanese (3.96). Interior smell was more important to Chinese (4.65) and Japanese (4.54) than to Koreans (4.02). Interior color was more important to Koreans (4.92) and Chinese (4.74) than to Japanese (4.49). Waiting time for seat- ing was more important to Koreans (4.94) and Japanese (4.87) than to Chinese (4.45). Accessibility was more important to Japanese (5.32) and Chinese (5.24) than to Koreans (4.95).

The following summarizes some noticeable results based on the previous analyses. First, the most influential domain for customer satisfaction was different among the three cities. The FRD, the IRD, and the CRD were the most important domains for Chinese, Japanese, and Koreans respectively. This result seems to reflect the character of customers in each city (or a stereotype of each country) quite well. This result also provides information for a key success factor for the business in that the food taste in the same type of restaurant franchise is commonly similar. For Koreans for example, the investment to improve the convenience of using the restaurant franchises might be a better strategy than decorating the restaurant to attract customers. Second, the IRD and SRD for Japanese and the FRD and CRD for Chinese and Koreans were more important domains. Interestingly, the importance of the SRD was higher in the country with the higher GDP per capita (Japan-South Korea-China). This result may show the tendency that the relative importance of the SRD has among FRD, IRD, SRD, and CRD will be growing in all countries as their economies grow. This also represents the relative importance of staff training for restaurant franchises in the long run. But, there were no significant differences among three cities in all domains except for the FRD. Third, the most influential element for customer satisfaction was slightly different among the three cities. Food taste was dominantly important for Chinese. For Japanese respondents, lighting, accessibility, and way of speaking were more important than food taste. For Korean's the waiting time for food was second next to food tastes. Interestingly, the importance of food decoration in Beijing was significantly higher than in Tokyo or in Seoul. These results can provide marketing guidelines for restaurant franchises in three cities. That is, excluding food taste, which should be important for any location, improving the quality of the element evaluated to be important in each city can an efficient way to increase customer satisfaction.

\section{Discussion and Conclusions}

The present study classified four domains and 24 elements in the customer experience at restaurant franchises based on the literature review. A survey to compare the three cities (Beijing, Tokyo, and Seoul) was then conducted. Thirteen elements were identified based on the factor analysis. The analyses showed that important domains and elements affecting customer satisfaction were very different among the three cities. In conclusion, this research supported the hypothesis that customer experience at restaurant franchises is influ- 
enced by four domains and elements in different degrees among three cities, Beijing, Tokyo, and Seoul. Based on the latter result, this study provides a customer experience management (CEM) guideline for restaurant franchisees in the three cities to increase customer satisfaction. This result supported the fact that implementing localized marketing strategies for a global restaurant franchise business could be an effective strategy to efficiently penetrate the market of the three cities.

Based on the statistical analyses introduced in Section 4, some strategies for customer experience management can be provided. For example, menu development, food globalization, or food localization can be important strategies in Beijing because the food taste there was the most important to customer satisfaction. Customizing illuminations depending on customer preference or the type of the restaurant should be very important in Tokyo. Some types of staff-related programs such as staff training, staff rewards, or a complaint reporting system might be applicable solutions to improve the SRD in Tokyo. To ensure speedy service or to make the waiting time for food less boring in Seoul, some novel approaches can be considered. Improving the service flow or redesigning the layout can decrease service time. Providing entertainment such as magazines is an inexpensive way for waiting customers to pass the time. To improve accessibility, providing free transportation (e.g., a shuttle bus) or advertising the restaurant franchise with directions to the nearest locations should be very helpful.

Despite the useful information the present study generated, some careful interpretations should be made. The differences in influential domains or elements of customer satisfaction among cities may arise from complicated reasons. The reasons can be classified into primary factors caused by service providers (restaurant franchisees) and secondary factors included in cultures. The primary factors are related directly to all services provided from the restaurant franchises. Having different lengths of history, restaurant franchises in the three cities may have different qualities of service, service knowhow, or service systems that cause customer satisfaction. The secondary factors (cultures) can also influence customers both directly and indirectly. Customer satisfaction is very subjective. Customers in different cultures (different cities or countries) may have different perceptions with the same experience. For example, food taste was commonly important to respondents in all three cities, but the present study did not inquire about which food taste was preferred. Take wall pictures as another example; the kind of pictures respondents like can be highly influenced by their cultures. In this regard, customer preferences and requirements for each domain and element need to be examined clearly to give a complete CEM guideline for a restaurant franchiser. Further studies with more diversified populations from the three countries will be necessary to generalize the results from this research considering that only three cities were compared.

\section{References}

Baker, J. and Cameron, M. (1996), The Effects of the Service Environment on Affect and Consumer Perception of Waiting Time : An Integrative Review and Research Propositions, Journal of the Academy of Marketing Science, 24(4), 338-349.

Bitner, M. J., Booms, B. H., and Tetreault, M. S. (1990), The Service Encounter : Diagnosing Favorable and Unfavorable Incidents, Journal of Marketing, 54(1), 71-84.

Chin, J. B. (2008), A Study of Taiwan Takeout Beverage Franchise Chain Business Performance Model, IEEE Xplore, 8(2), 1-5.

Cronbach, L. (1951), Coefficient Alpha and the Internal Structure of Tests, Psychometrika, 16(3), 297-334.

Clark, M. A. and Wood, R. C. (1998), Consumer Loyalty in the Restaurant Industry : A Preliminary Exploration of the Issues, International Journal of Contemporary Hospitality Management, 10(4), 139-144.

Davis, M. M. and Vollmann, T. E. (1990), A Framework for Relating Waiting Time and Customer Satisfaction in a Service Operation, Journal of Services Marketing, 4(1), 61-69.

Devaraj, S., Fan, M., and Kohli, R. (2002), Antecedents of B2C Channel Satisfaction and Preference : Validation E-Commerce Metrics, Information Systems Research, 13(3), 316-333.

Dube, L., Johnson, M. D., and Renaghan, L. M. (1999), Adapting the QFD Approach to Product Design in Extended Service Transactions, Production and Operations Management, 8(3), 301-317.

Erickson, K. (2004), Bodies at Work : Performing Wervice in American Restaurants, Space and Culture, 7(1), 76-89.

Fitzsimmons, J. A. and Maurer, G. B. (1991), A Walk-through Audit to Improve Restaurant Performance, The Cornell Hotel and Restaurant Administration Quarterly, 31(4), 94-99.

Gounaris, S. and Dimitriadis, S. (2003), Assessing Service Quality on the Web : Evidence from Business-to-Consumer Portals, Journal of Services Marketing, 17(5), 529-548.

Han, H. and Ryu, K. (2009), The Roles of the Physical Environment, Price Perception, and Customer Satisfaction in Determining Customer Loyalty in the Restaurant Industry, Journal of Hospitality and Tourism Research, 33(4), 487-510.

Jiang, J. J., Klein, G., and Carr, C. L. (2002), Measuring Information System Service Quality : SERVQUAL from the Other Side, MIS Quarterly, 26(2), 145-166.

Kivela, J., Inbakaran, R., and Reece, J. (2000), Consumer Research in the Restaurant Environment. Part 3 : Analysis, Findings and Conclusions, International Journal of Contemporary Hospitality Management, 12(1), 13-30.

Kang, H. and Bradley, G. (2002), Measuring the Performance of IT Services : An Assessment of SERVQUAL, International Journal of Accounting Information Systems, 3(3), 151-164.

Knutson, B. J. (2000), College Students and Fast Food : how Students Perceive Restaurant Brands, Cornell Hotel and Restaurant Administration Quarterly, 41(3), 68-74.

Lambert, C. U. and Watson, K. M. (1984), Restaurant Design : Researching the Effects on Customers, Cornell Hotel and Restaurant Administration Quarterly, 24(4), 68-76.

LaSalle, D. and Britton, T. A. (2003), Priceless : Turning Ordinary Products into Extraordinary Experiences, Harvard Business School Press, Boston, MA.

Lehto, M. R. and Buck, J. R. (2008), Introduction to Human Factors and Ergonomics for Engineers, Lawrence Erlbaum Associates, New York, 
NY.

Meyer, C. and Schwager, A. (2007), Understanding Customer Experience, Harvard Business Review, 85(2), 116-126.

Milliman, R. E. (1986), The Influence of Background Music on the Behavior of Restaurant Patrons, Journal of Consumer Research, 13(2), 286-289.

Mittal, B. and Lassar. W. M. (1996), The Role of Personalization in Service Encounters, Journal of Retailing, 72(1), 95-109.

Namkung, Y. and Jang, S. (2007), Does Food Quality Really Matter in Restaurants? Its Impact on Customer Satisfaction and Behavioral Intentions, Journal of Hospitality \& Tourism Research, 31(3), 387-410.

Parasuraman, A., Zeithaml, V. A., and Berry, L. L. (1988), SERVQUAL : A Multiple-Item Scale for Measuring Consumer Perceptions of Service Quality, Journal of Retailing, 6(1), 12-40.

Parsa, H. G. and Khan, M. A. (1989), Analysis of Menu Trends in Fast Food Industry, Journal of Hospitality Education and Research, 13(3), 545.

Pheng, L. S. and Yuquan, S. (2002), An Exploratory Study of Hofstede's Cross-Cultural Dimensions in Construction Projects, Management Decision, 40(1), 7-16.

Rubin, P. H. (1978). The Theory of the Firm and the Structure of the Franchise Contract, Journal of Law and Economics, 21(1), 223-233.

Ryu, K. and Jang, S. S. (2007), The Effect of Environmental Perceptions on Behavioral Intentions through Emotions : The Case of Upscale Restaurants, Journal of Hospitality and Tourism Research, 31(1), 56-72.

Schmitt, B. H. (1999), Experience Marketing : How to Get Customers to Sense, Feel, Think, Act, Relate to Your Company and Brands, Simon and Schuster Inc, New York, NY.

Shaw, C. and Ivens, J. (2005), Building Great Customer Experiences. Palgrave MacMillan, New York, NY.

Smith, A. K., Bolten, R. N., and Wagner, J. (1999), A Model of Customer Satisfaction with Service Encounters Involving Failure and Recovery, Journal of Marketing Research, 36(3), 356-372.

Smith, P. C. and Curnow, R. (1966), Arousal Hypothesis and the Effects of Music on Purchasing Behavior, Journal of Applied Psychology, 50(June), 255-286.

Sparrow, J, Ingold, T., Huyton, J., and Baker, J. (1992), Experienced Staff and Tailoring Food Service, International Journal of Contemporary Hospitality Management, 4(1), 4-10.

Sulek, J. M. and Hensley, R. L. (2004), The Relative Importance of Food, Atmosphere, and Fairness of Wait : the Case of a Full-Service Restaurant, Cornell Hotel and Restaurant Administration Quarterly, 45(3), 235-247.

Susskind, A. M. and Chan, E. K. (2000), How Restaurant Features Affect Check Averages : A Study of the Toronto Restaurant Market, Cornell Hotel and Restaurant Administration Quarterly, 42(6), 56-63.

Testa, M. R. and Sipe, L. J. (2006), A Systems Approach to Service Quality : Tools for Hospitality Leaders, Cornell Hotel and Restaurant Administration Quarterly, 47(1), 36-48.

Varki, S. and Colgate, M. (2001), Role of Price Perceptions in an Integrated Model of Behavioral Intentions, Journal of Service Research, 3(3),
232-240.

Wakefield, K. L. and Blodgett, J. G. (1996), The Effect of the Servicescape on Customers' Behavioral Intentions in Leisure Service Settings, Journal of Services Marketing, 10(6), 45-61.

Whyte, W. F. (1964), Part III. Human Relations in the Restaurant Industry, Cornell Hotel and Restaurant Administration Quarterly, 5, 35-47.

Zeithaml, V. A. (1988), Consumer Perceptions of Price, Quality, and Value : A Means-end Model and Synthesis of Evidence, The Journal of Marketing, 52(3), 2-22.

\section{<Appendix A> Questions of the Questionnaire}

Mark the following questions using 7-likert scale based on your experience at the restaurant franchise.

1. I was satisfied with the diversity of the menus.

2. I was satisfied with quantity or quality of the free side dishes.

3. The food taste was good to me.

4. I was satisfied with the food decoration.

5. The material for the food was fresh.

6. I was satisfied with the dish's design.

7. The menus were easy to read.

8. The seat layout was satisfactory.

9. I was satisfied with the interior lighting.

10. I was satisfied with the picture hanging on the wall.

11. The indoor smell was good.

12. The interior temperature was proper.

13. The interior color was good.

14. The background music of the restaurant was good.

15. I was satisfied with employees' attitude for service.

16. I was satisfied with way of speaking of employees.

17. The employees quickly responded to customers' order.

18. The number of employees was enough for service.

19. The employees were clean.

20. The restaurant was easy to go.

21. I was satisfied with the waiting time for seating.

22. I was satisfied with the waiting place for seating.

23. I was satisfied with the waiting time for food after being seated.

24. The meal fee was reasonable.

25. I was satisfied with the restaurant franchise. 